\title{
The Role of Diet and Supplementation of Natural Products in COVID-19 Prevention
}

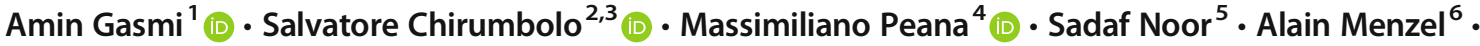 \\ Maryam Dadar $^{7}$ (D) $\cdot$ Geir Bjørklund ${ }^{8}$ (D)
}

Received: 3 December 2020 / Accepted: 1 February 2021 / Published online: 25 February 2021

(C) The Author(s), under exclusive licence to Springer Science+Business Media, LLC part of Springer Nature 2021

\begin{abstract}
Recently, a discussion has begun on the global management strategy against COVID-19 based on the hypothesis that individuals' macro- and micronutrient status combined with antiviral drugs and herbs can be an ally against the infection. The hypothesis is that people's nutritional and oxidative scavenging capacity may provide fundamental data to predict severe and acute pulmonary distress following SARS-Cov2 infection. Consequently, the scientific community has addressed the role of balanced diets, nutritional supplements, and micronutrients, including folk herbal formulations, in reducing hospitalization and the severity of pulmonary impact in COVID-19 by preventing the most serious forms of the infection. This led to an animated debate on the potential effectiveness of some vitamins, micronutrients, and traditional Chinese medicine in preventing COVID-19, with some authors convinced that plant extracts could act oppositely, exacerbating the effect of the infection. While current research is still far to assess the suggestions and issues raised in this short communication, it is undoubtedly true that determining an individual's current metabolic status, including macro- and micronutrients, is an essential factor in defining any individuals' deficiencies, which will need to be addressed urgently through a proper diet, specific personalized nutritional supplementation, and lifestyle changes.
\end{abstract}

Keywords Immunomodulation · COVID-19 · SARs-CoV-2 $\cdot$ Nutrients · Vitamins $\cdot$ Trace elements $\cdot$ Natural products $\cdot$ Dietary habits

The scientific community has recently addressed the role of balanced diets, nutrients from raw food and natural products,

Geir Bjørklund

bjorklund@conem.org

1 Société Francophone de Nutrithérapie et de Nutrigénétique Appliquée, Villeurbanne, France

2 Department of Neurosciences, Biomedicine and Movement Sciences, University of Verona, Verona, Italy

3 CONEM Scientific Secretary, Verona, Italy

4 Department of Chemistry and Pharmacy, University of Sassari, Sassari, Italy

5 Institute of Molecular Biology and Biotechnology, Bahauddin Zakariya University, Multan, Pakistan

6 Laboratoires Réunis, Junglinster, Luxembourg

7 Razi Vaccine and Serum Research Institute, Agricultural Research, Education and Extension Organization (AREEO), Karaj, Iran

8 Council for Nutritional and Environmental Medicine (CONEM), Toften 24, 8610 Mo i Rana, Norway and micronutrients, including folk herbal formulations such as Chinese medicine, in reducing hospitalization and the severity of pulmonary impact in COVID-19 by preventing the most serious and exacerbated forms of the infection $[1,2]$. The general idea underlying this approach is that COVID-19 has an extraordinarily complex spectrum of clinical processes. These include the individual's ability to limit the severity of the infection's development through immunity, genetics, lifestyle, and environment. Therefore, people's nutritional and oxidative scavenging capacity may provide fundamental data to predict severe and acute pulmonary distress following SARS-Cov2 infection [3-6]. Despite some concerns about the possible toxicity of many xenobiotic compounds retrieved from plant extracts on the market, natural products in the diet may reduce COVID-19 exacerbation following viral infections [1]. Undoubtedly, COVID-19 remains a complex pathology where there is a significant association with metabolic disorders, particularly with obesity-related hypertension, usually associated with the elderly and the infection's course/ progression [7-9]. Therefore, a fundamental question would be: Does an optimized diet prevent the onset of COVID-19 
despite viral exposition? The challenge is to improve diet and lifestyle to reduce the impact of comorbidities related to metabolic imbalance [10-13]. A recent comment by Young and Zampella [14] addressed two areas of concern, including the discussion of the potential antiviral properties of some herbal products, such as Withania somnifera $L$. and some natural derived extracts [1]. The ability of withanolides from Withania somnifera L. (or ashwagandha), particularly withanoside 5 , exhibits very high molecular docking properties and binding affinity against SARS-CoV2 components and makes promising use of some folk medicine to fight the clinical consequences of the COVID-19 outbreak [15].

On the contrary, some authors are convinced that plant extracts may exacerbate COVID-19 [14]. Natural products acting, for example, on such mechanisms exacerbated during COVID-19, such as pulmonary hypertension, notoriously borne by Glycyrrhiza glabra extracts, should be further examined in docking research to gather those compounds able to provide benefits in COVID-19 patients [16]. Important clinical trials are also planned to highlight which type of herbal extracts can address COVID-19 [17, 18]. The issue of using folk medicine is fundamental for at least two reasons. First, it is an approach highly adopted in South East Asian countries and China, where the COVID-19 outbreak began, and second it is a potential source of suggestions for new important therapeutic drugs against SARS-CoV2.

Very recently, Gasmi et al. discussed the individuals' macroand micronutrient status combined with antiviral medication and herbs in order to establish a comprehensive management strategy of both edible and pharmaceutical natural products to be used against COVID-19 [1]. The commonest micronutrients able to determine the clinical course of individual COVID-19 include vitamins D, A, and C, selenium, and zinc [12, 19]. However, more investigation is needed into other micronutrients, whose depletion or insufficient uptake may exacerbate COVID-19 [12]. There has been an animated debate on the role that vitamin D [20], essential amino acids, branched amino acids, polyunsaturated fatty acids (PUFAs), and other micronutrients play in COVID-19 prevention [21]. Furthermore, some medications and specific herbal products were recently discussed as potential therapeutic options according to their particular antiviral mechanism based on previous research about SARS-CoV and MERS-CoV [2, 22-24]. Agreement in this regard can be extremely hard to be achieved without further good-quality studies. For example, criticism was raised on the previous report [14] regarding the potential toxicity of substances such as Echinacea purpurea (purple coneflower), Astragalus (milkvetch), Pelargonium sidoides (African geranium), curcumin, propolis, Glycyrrhiza glabra (licorice) root, and glycyrrhizin [14], when these herbs have never been mentioned [1]. More than $85 \%$ of patients infected with SARS-CoV2 in China received certain types of traditional Chinese medicine (TCM) preparations as a part of their treatment [25]. These remedies' allergic and anaphylactic potentials are poor and warrant their safety, though vigilance is mandatory [26]. China and South Korea released national guidelines for traditional medicinal treatment on COVID-19 [27]. They stress the possibility that herbal extracts could be noxious for patients with COVID-19 might be the logical consequence of a psychological attitude from the increasing belief that COVID-19 is worsening worldwide. Based on historical records and human evidence of SARS and H1N1 influenza prevention, the Chinese herbal formula could be an alternative approach for preventing COVID-19 in high-risk populations. Prospective, rigorous population studies are warranted to confirm the potential preventive effect of TCM. Despite this, there is mounting evidence that metabolic disorders, as a comorbidity of severe forms of COVID-19, are more frequent, therefore addressing diet and balancing them with supplementation, which may improve COVID-19 therapy [12].

For example, an individual with proven zinc insufficiency or deficiency could consider zinc supplementation as a sensible option to improve their micronutrient status during pandemics [28-31]. Zinc is fundamental to fight against SARS$\mathrm{CoV} 2$ infection as this cofactor is of the utmost importance for ROS scavenging and reduction of the stress response, which can lead, particularly in the elderly, to exacerbated forms of pneumonia caused by COVID-19 [6, 32, 33].

Gasmi et al. [1] focused on the individual risk management strategy during this period without defined treatment for the general population. The determination of an individual's current metabolic status, including macro- and micronutrients, is essential. Any individuals' deficiencies need to be corrected through diet, nutrition, lifestyle, and environmental changes.

However, very few clinical trials or observational case or cohort studies are available to assess the suggestions and issues raised in this short communication [34-36]. The proper collection of dietary habits among different populations, with the available raw food and natural sources, is a major task of the WHO engagement to address the pandemic and manage the emergency. Physicians should advise for the better diet available to reduce the impact of pneumonia and better manage possible hospitalizations. The big concern of a correct dietary habit and lifestyle is not pleonastic and can address the coronavirus disease in a much more correct approach. Whereas most advertising about herbal medicine tends to discourage the use of natural products to prevent the onset of severe pneumonia, a correct diet optimizes both gut and lung microbiomes, allowing the subject to prevent any involutive course towards COVID-19 caused-ARDS. Utilizing new plant-derived drugs as a therapy against COVID-19 is still a long way from being realized. However, a thorough investigation of the immune-metabolic status of people who might be infected with SARS-Cov2, by studying their daily life habits and diets, based on their folk traditions and geographical distribution, is mandatory for science. 
Data Availability Not applicable.

\section{Declarations}

Conflict of Interest The authors declare no competing interests.

\section{References}

1. Gasmi A, Noor S, Tippairote T, Dadar M, Menzel A, Bjørklund G (2020) Individual risk management strategy and potential therapeutic options for the COVID-19 pandemic. Clin Immunol 215: 108409. https://doi.org/10.1016/j.clim.2020.108409

2. Mani JS, Johnson JB, Steel JC, Broszczak DA, Neilsen PM, Walsh KB, Naiker M (2020) Natural product-derived phytochemicals as potential agents against coronaviruses: a review. Virus Res 284: 197989. https://doi.org/10.1016/j.virusres.2020.197989

3. Stoian AP, Toth PP, Kempler P, Rizzo M (2020) Gender differences in the battle against COVID-19: impact of genetics, comorbidities, inflammation and lifestyle on differences in outcomes. Int J Clin Pract:e13666. https://doi.org/10.1111/ijcp.13666

4. De Sio S, Buomprisco G, La Torre G, Lapteva E, Perri R, Greco E, Mucci N, Cedrone F (2020) The impact of COVID-19 on doctors' well-being: results of a web survey during the lockdown in Italy. Eur Rev Med Pharmacol Sci 24 (14):7869-7879. 10.26355/ eurrev 20200722292

5. Bermano G, Méplan C, Mercer DK, Hesketh JE (2020) Selenium and viral infection: are there lessons for COVID-19? Br J Nutr:137. https://doi.org/10.1017/s0007114520003128

6. de Almeida Brasiel PG (2020) The key role of zinc in elderly immunity: a possible approach in the COVID-19 crisis. Clin Nutr ESPEN 38:65-66. https://doi.org/10.1016/j.clnesp.2020.06.003

7. Kassir R (2020) Risk of COVID-19 for patients with obesity. Obes Rev 21(6):e13034-e13034. https://doi.org/10.1111/obr.13034

8. Stefan N, Birkenfeld AL, Schulze MB, Ludwig DS (2020) Obesity and impaired metabolic health in patients with COVID-19. Nat Rev Endocrinol 16(7):341-342. https://doi.org/10.1038/s41574-0200364-6

9. Gasmi A, Peana M, Pivina L, Srinath S, Gasmi Benahmed A, Semenova Y, Menzel A, Dadar M, Bjorklund G (2020) Interrelations between COVID-19 and other disorders. Clin Immunol 224:108651. https://doi.org/10.1016/j.clim.2020.108651

10. Butler MJ, Barrientos RM (2020) The impact of nutrition on COVID-19 susceptibility and long-term consequences. Brain Behav Immun 87:53-54. https://doi.org/10.1016/j.bbi.2020.04.040

11. Barazzoni R, Bischoff SC, Breda J, Wickramasinghe K, Krznaric Z, Nitzan D, Pirlich M, Singer P (2020) ESPEN expert statements and practical guidance for nutritional management of individuals with SARS-CoV-2 infection. Clin Nutr 39(6):1631-1638. https://doi. org/10.1016/j.clnu.2020.03.022

12. Gasmi A, Tippairote T, Mujawdiya PK, Peana M, Menzel A, Dadar M, Benahmed AG, Bjørklund G (2020) Micronutrients as immunomodulatory tools for COVID-19 management. Clin Immunol: 108545. https://doi.org/10.1016/j.clim.2020.108545

13. Jayawardena R, Sooriyaarachchi $\mathrm{P}$, Chourdakis M, Jeewandara C, Ranasinghe P (2020) Enhancing immunity in viral infections, with special emphasis on COVID-19: a review. Diabetes Metab Syndr 14(4):367-382. https://doi.org/10.1016/j.dsx.2020.04.015

14. Young TK, Zampella JG (2020) Supplements for COVID-19: a modifiable environmental risk. Clin Immunol 216:108465. https:// doi.org/10.1016/j.clim.2020.108465

15. Tripathi MK, Singh P, Sharma S, Singh TP, Ethayathulla AS, Kaur $P$ (2020) Identification of bioactive molecule from Withania somnifera (Ashwagandha) as SARS-CoV-2 main protease inhibitor. J Biomol Struct Dyn:1-14. https://doi.org/10.1080/ 07391102.2020 .1790425

16. Shawky E, Nada AA, Ibrahim RS (2020) Potential role of medicinal plants and their constituents in the mitigation of SARS-CoV-2: identifying related therapeutic targets using network pharmacology and molecular docking analyses. RSC Adv 10(47):27961-27983. https://doi.org/10.1039/d0ra05126h

17. Kanjanasirirat P, Suksatu A, Manopwisedjaroen S, Munyoo B, Tuchinda P, Jearawuttanakul K, Seemakhan S, Charoensutthivarakul S, Wongtrakoongate P, Rangkasenee N, Pitiporn S, Waranuch N, Chabang N, Khemawoot P, Sangiamsuntorn K, Pewkliang Y, Thongsri P, Chutipongtanate S, Hongeng S, Borwornpinyo S, Thitithanyanont A (2020) Highcontent screening of Thai medicinal plants reveals Boesenbergia rotunda extract and its component Panduratin A as anti-SARSCoV-2 agents. Scientific Reports 10(1):19963. https://doi.org/10. 1038/s41598-020-77003-3

18. Wang ZY, Fu SZ, Xu L, Li SS, Qian KJ, He XD, Zhu GC, Li LH, Zhang J, Li WF, Qin BY, Zhou CL, Ma PL (2020) Impact of Shenfu injection on a composite of organ dysfunction development in critically ill patients with coronavirus disease 2019 (COVID-19): a structured summary of a study protocol for a randomized controlled trial. Trials 21(1):738. https://doi.org/10.1186/s13063-02004677-5

19. Beigmohammadi MT, Bitarafan S, Hoseindokht A, Abdollahi A, Amoozadeh L, Mahmoodi Ali Abadi M, Foroumandi M (2020) Impact of vitamins A, B, C, D, and E supplementation on improvement and mortality rate in ICU patients with coronavirus-19: a structured summary of a study protocol for a randomized controlled trial. Trials 21(1):614. https://doi.org/10.1186/s13063-020-04547-0

20. Rabbitt L, Slattery E (2020) Vitamin D and Covid-19: a note of caution. Ir Med J 113(5):82

21. Rozga M, Cheng FW, Moloney L, Handu D (2020) Effects of micronutrients or conditional amino acids on COVID-19-related outcomes: an evidence analysis center scoping review. J Acad Nutr Diet. https://doi.org/10.1016/j.jand.2020.05.015

22. Wyganowska-Swiatkowska M, Nohawica M, Grocholewicz K, Nowak G (2020) Influence of herbal medicines on HMGB1 release, SARS-CoV-2 viral attachment, acute respiratory failure, and sepsis. A literature review. Int J Mol Sci 21(13). https://doi. org/10.3390/ijms 21134639

23. Chiow KH, Phoon MC, Putti T, Tan BK, Chow VT (2016) Evaluation of antiviral activities of Houttuynia cordata Thunb. extract, quercetin, quercetrin and cinanserin on murine coronavirus and dengue virus infection. Asian Pac J Trop Med 9(1):1-7. https:// doi.org/10.1016/j.apjtm.2015.12.002

24. Ryu YB, Jeong HJ, Kim JH, Kim YM, Park JY, Kim D, Nguyen TT, Park SJ, Chang JS, Park KH, Rho MC, Lee WS (2010) Biflavonoids from Torreya nucifera displaying SARS-CoV 3CL(pro) inhibition. Bioorg Med Chem 18(22):7940-7947. https://doi.org/10.1016/j.bmc.2010.09.035

25. Yang Y, Islam MS, Wang J, Li Y, Chen X (2020) Traditional Chinese medicine in the treatment of patients infected with 2019new coronavirus (SARS-CoV-2): a review and perspective. Int $\mathrm{J}$ Biol Sci 16(10):1708-1717. https://doi.org/10.7150/ijbs.45538

26. Pokladnikova J, Meyboom RH, Meincke R, Niedrig D, Russmann S (2016) Allergy-like immediate reactions with herbal medicines: a retrospective study using data from VigiBase(R). Drug Saf 39(5): 455-464. https://doi.org/10.1007/s40264-016-0401-5

27. Luo H, Tang Q-L, Shang Y-X, Liang S-B, Yang M, Robinson N, Liu J-P (2020) Can Chinese medicine be used for prevention of corona virus disease 2019 (COVID-19)? A review of historical classics, research evidence and current prevention programs. Chin J Integr Med 26(4):243-250. https://doi.org/10.1007/s11655-0203192-6 
28. Hojyo S, Fukada T (2016) Roles of zinc signaling in the immune system. J Immunol Res 2016:6762343-6762321. https://doi.org/ $10.1155 / 2016 / 6762343$

29. Krenn BM, Gaudernak E, Holzer B, Lanke K, Van Kuppeveld FJ, Seipelt J (2009) Antiviral activity of the zinc ionophores pyrithione and hinokitiol against picornavirus infections. J Virol 83(1):58-64. https://doi.org/10.1128/JVI.01543-08

30. Wei Z, Burwinkel M, Palissa C, Ephraim E, Schmidt MF (2012) Antiviral activity of zinc salts against transmissible gastroenteritis virus in vitro. Vet Microbiol 160(3-4):468-472. https://doi.org/10. 1016/j.vetmic.2012.06.019

31. Gombart AF, Pierre A, Maggini S (2020) A review of micronutrients and the immune system-working in harmony to reduce the risk of infection. Nutrients 12(1). https://doi.org/10. 3390/nu12010236

32. Khurana AK, Karna ST, Hussain A (2021) Zinc and coronavirus disease 2019: causal or casual association? Chest 159(1):449-450. https://doi.org/10.1016/j.chest.2020.08.2092

33. Joachimiak MP (2021) Zinc against COVID-19? Symptom surveillance and deficiency risk groups. PLoS Negl Trop Dis 15(1): e0008895. https://doi.org/10.1371/journal.pntd.0008895
34. Yan B-H, Jiang Z-W, Zeng J-P, Tang J-Y, Ding H, Xia J-L, Qin SR, Jin S-C, Lu Y, Zhang N (2020) Large-scale prospective clinical study on prophylactic intervention of COVID-19 in community population using Huoxiang Zhengqi Oral Liquid and Jinhao Jiere Granules. Zhongguo Zhong Yao Za Zhi 45(13):2993-3000

35. Wang X, Xie P, Sun G, Deng Z, Zhao M, Bao S, Zhou Y (2020) A systematic review and meta-analysis of the efficacy and safety of western medicine routine treatment combined with Chinese herbal medicine in the treatment of COVID-19. Medicine (Baltimore) 99(32):e21616. https://doi.org/10.1097/MD.0000000000021616

36. Huang S-T, Lai H-C, Lin Y-C, Huang W-T, Hung H-H, Ou S-C, Lin H-J, Hung M-C (2020) Principles and treatment strategies for the use of Chinese herbal medicine in patients at different stages of coronavirus infection. Am J Cancer Res 10(7):2010-2031

Publisher's Note Springer Nature remains neutral with regard to jurisdictional claims in published maps and institutional affiliations. 